\title{
Preliminary Synchronized Phasor Data Analysis of Disturbance Events in the US Eastern Interconnection
}

\author{
Joe H. Chow, Luigi Vanfretti, Andrew Armenia, Scott Ghiocel, Sanjoy Sarawgi, Navin Bhatt, David \\ Bertagnolli, Meera Shukla, Xiaochuan Luo, Dean Ellis, Dawei Fan, Mahendra Patel, Andrew M. \\ Hunter, David E. Barber, and Gary L. Kobet
}

\begin{abstract}
This paper presents analysis results of synchronized phasor data from 10 disturbance events recorded in the US Eastern Interconnection (EI). The phasor data covers a wide region in the EI, allowing for the study of disturbance propagation, interarea modes, and oscillations in voltages and currents. The analysis is not straightforward because the EI is a meshed system with adequate interarea mode damping. Disturbances involving tripping a single large generator unit produce very short interarea swing responses. Islanding events involving regions at the perimeter, however, provide more prominent responses for analysis.
\end{abstract}

Index Terms-Synchronized phasor measurement data, phasor measurement units, disturbance analysis, US Eastern Interconnection

\section{INTRODUCTION}

$\mathrm{T}$ HE US Eastern Interconnection (EI) is a tightly meshed power grid with many regional control areas. It consists of the power system in eastern US and Canada, extending from the Atlantic Ocean to the Rocky Mountains, excluding Quebec and Texas. Many control regions have significant transfer paths and interchange agreements with neighboring regions. Despite the high level of power transfer, the network can be considered quite strong, since it does not have lightly damped interarea modes, which are quite prevalent in the Western US Power System [1]. As a result, with the exception of several blackout studies [2, 3, 4], the disturbance response of EI has not been studied extensively [5, 6]. However, as a result of the 2003 August 14 NE US blackout,

J. H. Chow, L. Vanfretti, A. Armenia, and S. Ghiocel are with Rensselaer Polytechnic Institute, Troy, NY 12180, USA (e-mail: chowj@rpi.edu, vanfrl@rpi.edu, andrew@asquaredlabs.com, ghiocs@rpi.edu).

S. Sarawgi and Navin Bhatt are with American Electric Power, Gahanna, OH 43230, USA (sksarawgi, Navin_bhatt@aep.com).

D. Bertagnolli, M. Shukla, and X. Luo are with ISO-New England, Holyoke, MA 01040, USA (e-mail:dbertagnolli, mshukla, xluo@iso-ne.com).

D. Ellis and D. Fan are with NYISO, Rensselaer, NY 12144 (email:dellis, dfan@nyiso.com).

M. Patel is with PJM Interconnection, Norris Town, PA 19403 (email:patelm3@pjm.com).

A. M. Hunter and D. E. Barber are with FirstEnergy, Reading, PA 19612 (amhunter, debarber@firstenergycorp.com).

G. L. Kobet is with TVA, Chattanooga, TN 37402, USA (glkobet@tva.gov).

This work is supported in part by AEP, FirstEnergy, NE-ISO, NYISO, and PJM, and by NSF through grant ECS-0622119. the North American Synchro-Phasor Initiative (NASPI) [7] was organized by the North American Electric Reliability Council (NERC), to install phasor measurement units (PMU) [8] across the EI so stresses in power systems across control regions can be better assessed.

One of the NASPI activities is the establishment of a Super Phasor Data Concentrator (SPDC) located at the Tennessee Valley Authority (TVA) to collect via the Internet phasor data from PMUs located in many control regions. PMU data from the SPDC was given to the Rensselaer research team for significant disturbance events in 2007 and 2008, ten of which are listed in Table 1. These PMU data from the TVA SPDC were supplemented by data retrieved directly from the PMUs and other PDCs.

This paper provides some preliminary analysis of the disturbance data. The scope of the work is not to identify the cause of the events, but rather, how the disturbances spread to the other regions and the disturbance responses observed. Furthermore, the disturbance analysis will focus on extracting certain common features from the disturbances. We will analyze interarea oscillatory modes, but exclude local oscillations such as those due to line trips, which generally have a small geographical impact.

The paper is organized as follows. In Section II, we provide the locations of the disturbance events and PMUs whose data will be analyzed,. In Section III, a scheme to handle the large amount of PMU data for each event is discussed. Section VI provides data analysis in the time domain, from the initial transient to the post-disturbance state. Section V discusses frequency domain analysis, where we compute the interarea mode frequencies and damping, using data from multiple channels simultaneously.

\section{II.PMU LOCATIONS AND DISTURBANCE EVENTS}

The Power System Research Consortium (PSRC), consisting of research teams from four universities (Rensselaer Polytechnic Institute, Virginia Tech, Univ. of Wyoming, and Montana Tech), was founded to develop tools for PMU data analysis. Data can be made available to PSRC by the Industry Members (AEP, FirstEnergy, ISO-NE, NYISO, and PJM) and TVA. For this paper, data were obtained from the 26 PMUs shown in Fig. 1. Note that not all PMU data were available for all events, so some entries in Table 1 are left blank. 
TABLE 1. SUMMARY OF DISTURBANCE EVENTS

\begin{tabular}{|c|c|c|c|c|c|c|}
\hline \multirow{2}{*}{ DISTURBANCE EVENT } & \multirow{2}{*}{ DATE } & \multirow{2}{*}{$\begin{array}{c}\text { FREQUENCY } \\
\text { CHANGE* }\end{array}$} & \multirow{2}{*}{ MW CHANGE } & \multirow{2}{*}{$\begin{array}{c}\beta \\
(\mathrm{MW} / 0.1 \mathrm{~Hz})\end{array}$} & \multicolumn{2}{|c|}{ CHANGE OF ANGLE* } \\
\hline & & & & & NY-AEP & NY-TVA \\
\hline $\begin{array}{l}\text { 1. Substation trip in Ontario. } \\
\text { 2. Loss of a generation unit in TVA. } \\
\text { 3. Loss of two generation units in South Carolina. } \\
\text { 4. Loss of a generation unit in Indiana. } \\
\text { 5. Loss of a generation unit in Ohio. } \\
\text { 6. Generation trip in Ohio. } \\
\text { 7. Islanding of Northwestern part in the Eastern Interconnection. } \\
\text { 8. Loss of HVDC in New England. } \\
\text { 9. Loss of generation and load in Oklahoma due to ice storm. } \\
\text { 10.Islanding of Maritime Provinces. }\end{array}$ & $\begin{array}{l}01 / 30 / 2007 \\
02 / 09 / 2007 \\
02 / 15 / 2007 \\
03 / 13 / 2007 \\
03 / 23 / 2007 \\
08 / 04 / 2007 \\
09 / 18 / 2007 \\
11 / 16 / 2007 \\
12 / 11 / 2007 \\
01 / 31 / 2008\end{array}$ & $\begin{array}{r}+39 \mathrm{mHz} \\
-35 \mathrm{mHz} \\
-50 \mathrm{mHz} \\
-40 \mathrm{mHz} \\
-55 \mathrm{mHz} \\
-117 \mathrm{mHz} \\
-65 \mathrm{mHz} \\
-37 \mathrm{mHz} \\
-80 \mathrm{mHz} \\
-30 \mathrm{mHz}\end{array}$ & $\begin{array}{l}+1170 \mathrm{MW} * * \\
-1200 \mathrm{MW} \\
-1692 \mathrm{MW} \\
-1200 \mathrm{MW} * * \\
-1285 \mathrm{MW} \\
-3600 \mathrm{MW}^{* *} \\
-1950 \mathrm{MW} * * \\
-1419 \mathrm{MW} \\
-2400 \mathrm{MW}^{* *} \\
-900 \mathrm{MW}^{* *}\end{array}$ & $\begin{array}{l}3429 \\
3384 \\
2336\end{array}$ & $\begin{array}{c}+4^{\circ} \\
+4^{\circ} \\
+5.5^{\circ}\end{array}$ & $\begin{array}{l}+6^{\circ} \\
+5^{\circ} \\
-7^{\circ}\end{array}$ \\
\hline
\end{tabular}

* Approximate values. ** Calculated using $\beta=3000 \mathrm{MW} / 0.1 \mathrm{~Hz}$

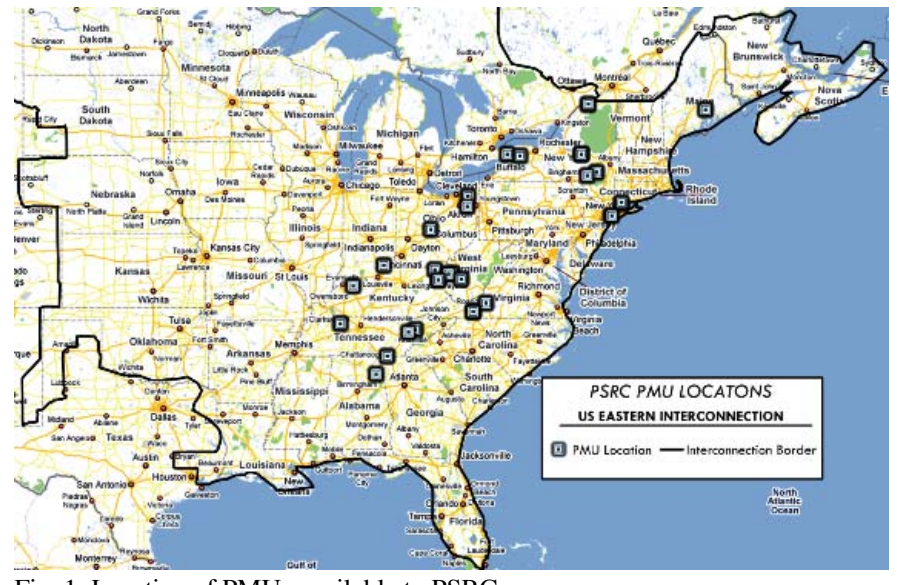

Fig. 1. Location of PMUs available to PSRC

We have selected the events in Table 1 because they involve changes in generation and load, which are usually flagged by the rate-of-frequency-change $(d f / d t)$ trigger. Line switching events are not included because such switchings would only readjust the flows on the nearby lines, without major impacts on the neighboring areas. The net changes in power are also listed in Table 1. For some of the generator trips, the pre-fault generations were known, from which we can calculate the frequency regulation constant $\beta$. For events where the generator output was not known or loads were involved, we used a $\beta$ of $3,000 \mathrm{MW} / 0.1 \mathrm{~Hz}$ in order to estimate the MW change [5].

Events 6 and 9 had the largest frequency variations and hence the largest change in MW also, but they did not result in significant oscillations. In Event 6, an initial fast frequency drop was followed by a slower decline, typical of a boiler runback in steam plants. Such a slower decline is much less disruptive to the power system and hence the system characteristics are not as apparent in the time responses. Event 9 occurred in a part of the system remote and not strongly connected to the Northeastern part of the EI. Thus the PMUs in Fig. 1 did not record a strong response.

The two events of most interest are Events 7 and 10, which were disturbances resulting in the islanding two of the corners of the EI. The analysis of some of the events is provided in Sections IV and V.

\section{PMU Data MANAGEMENT}

\section{A. Data Issues in the Startup Stage}

At this initial stage of the NASPI project, there are a number of disparities in the data set. Although most of the PMUs send data to the SPDC at 30 samples per second, there are PMUs with other sampling rates, such as 6 or 10 samples per second. Occasionally, data were lost during the internet transmission due to the lack of bandwidth. On other occasions, a PMU would be offline for upgrading hardware, software, and communication capability. However, some of the data problems, such as phase shifts due to a different phase sequence and CT/PT scalings, can be readily compensated for.

As the NASPI project matures, many of these data issues will be resolved. For the time being, our investigation will be limited due to incomplete data.

\section{B. PMU Data Processing Techniques}

\section{1) Data Conversion Techniques}

Unlike the WECC, where the .dst format has been adopted for data exchange [9], the EI currently has no standard way of sharing data. Moreover, the PMU data analyzed here is not necessarily extracted from a single PDC.

The EI PMU Data is available from different sources: PMUs, IEDs, and PDCs. In addition to the different sources, the data is also exchanged in many different formats: COMTRADE [10] .cfg and .dat files, delimited text files such as .csv and MS Excel files, and database files from MS Access and MySQL. To handle the diversity of data sources and data formats, we have developed a PMU Data Conversion framework.

The framework consists of consolidating PDC Data and device specific data as shown in Fig. 2. Each of the data conversion techniques deals with one data source. When the data comes from a PDC in text delimited format, a MySQL database is generated using the MySQL Client for MATLAB [11] or an Access database is generated using Visual Basic Macros. After the database is created (or when the database is available beforehand), either the MATLAB Database Toolbox [12] or the MySQL Client for MATLAB is used to create a MATLAB class. 
When the data come from individual devices, a custom conversion routine has to be written for each PMU and data format. At the final stage, MATLAB data structures and classes are obtained. Observe that both techniques result in the same MATLAB class format, enabling the development of software applications.

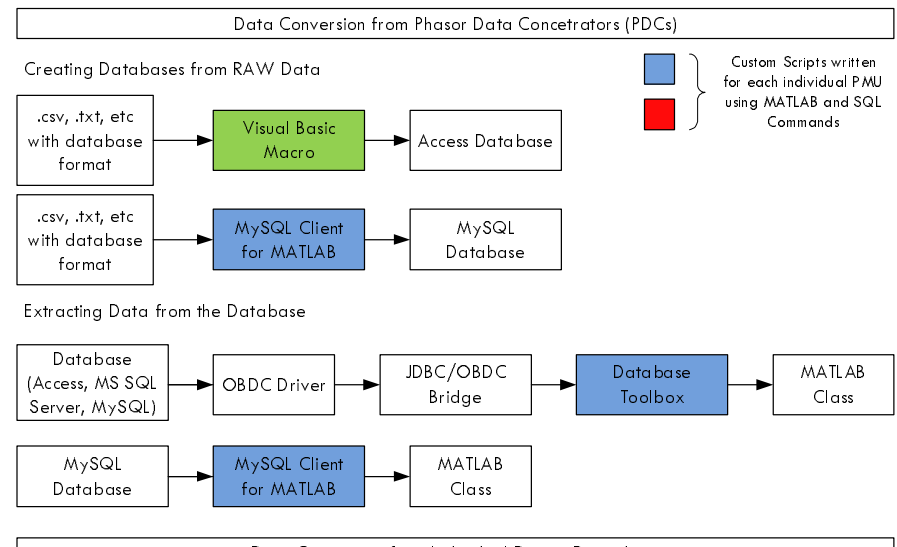

Data Conversion from Individual Device Recordings

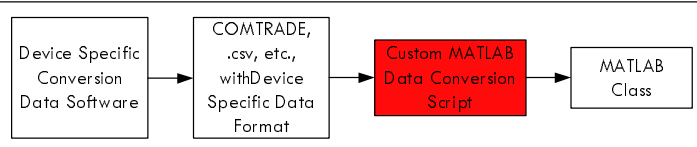

Fig. 2. Data conversion framework

\section{2) PMU Data Handling}

Using the techniques described above, we have created a repository of MATLAB data organized in classes for each event. Data structures and classes provide a compact and organized mean to handle PMU data for analysis: each PMU can be defined as a class, and each channel from the PMU can be defined as a field. To illustrate these features, some of the fields of the class for the PMU at Volunteer (TVA) are shown below: volu $=$

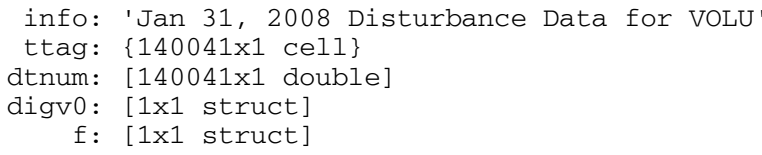

Data analysis can be readily carried out by having all the data stored in data structures. Operations, manipulation, and visualization can be standardized and done quickly. Observe that the resulting class has different kinds of data structures, giving the maximum amount of data available for analysis and software development. As an illustration, the field volu.f includes information on the frequency channel. The use of data structures allows the inclusion of not only the data, but also specific information on the channel:

>> volu.f

ans $=$

data: [140041x1 double]

info: 'Channel 75: Volunteer ABB-521 Frequency'

The features highlighted above have been used for data analysis and software development related to this paper.

3) Further Application of OOP Concepts for Data Processing and Software Development

With the latest object-oriented programming (OOP) features implemented in MATLAB R2008a, it is possible to apply OOP concepts for PMU data management for data processing, software development, and data exchange. These features can be used for error checking, controlling data access, and implementation of methods, etc. This approach will allow the software to be easier to use and maintain, while providing a platform for the development of new applications.

\section{Disturbance Propagation}

\section{A. Disturbance detection using bus frequency}

In an interconnected power system, the impact of a disturbance will spread to neighboring regions and beyond. The papers [13-15] provide analysis on how power imbalances travel as electromechanical waves on the transmission lines. This disturbance propagation is most readily seen by observing the bus frequencies.

Events 7 and 10 clearly demonstrate the validity of the concepts in [13-15]. Fig. 3 shows the disturbance in Event 7 traveling from west to east, reaching the PMUs in TVA and Virginia before the PMU in New York. Fig. 4 shows the disturbance in Event 10 traveling from east to west, reaching first the PMU in New York, then the PMU in Ohio, before the TVA and Virginia PMUs.

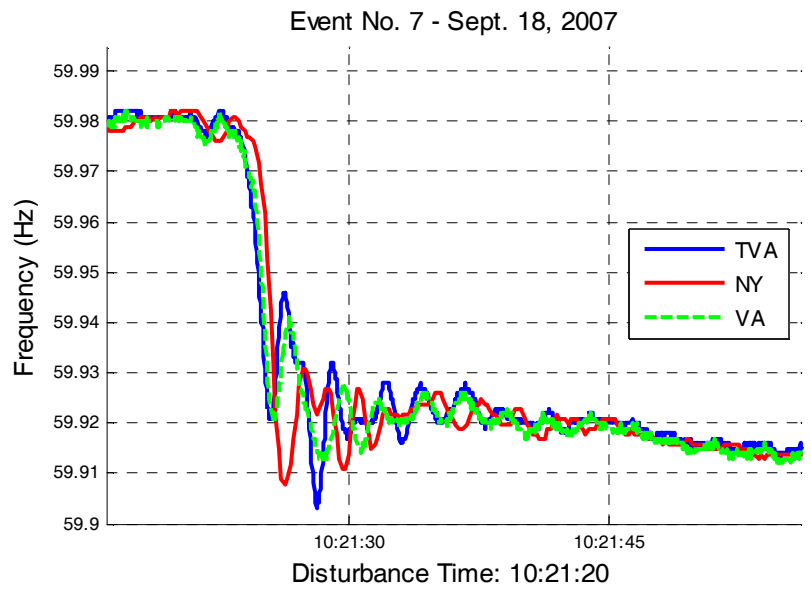

Fig. 3. Frequencies measured by PMUs in three different regions

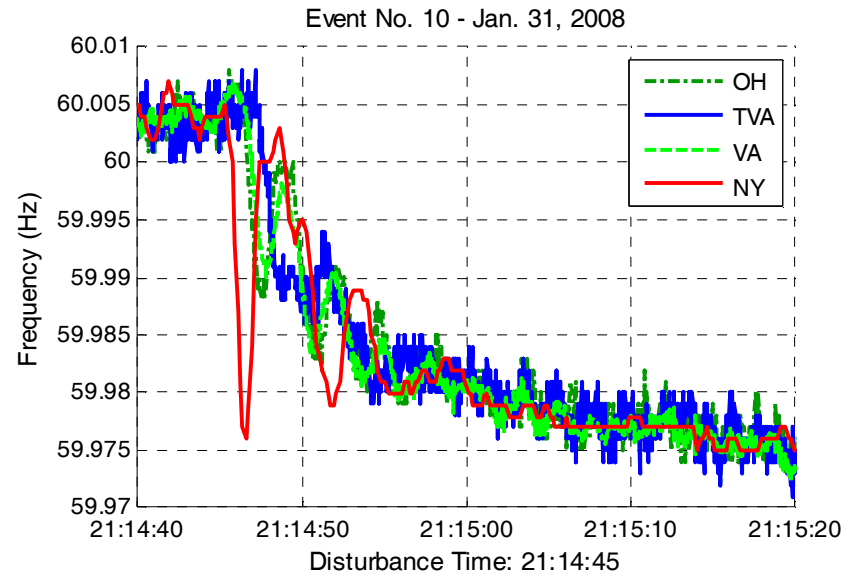

Fig. 4. Frequencies measured by PMU's in four different regions in the Maritime event 
These plots also show the difficulties in trying to estimate the direction and location of the disturbance location. The disturbance travel time between NY and VA for Event 6 was 0.65 seconds, and for Event 10 was 1.38 seconds. These travel times are different because there are many parallel transfer paths. An expert system for locating generator trip based on the FNET data is described in [16].

\section{B. Disturbance responses in bus voltage and line current}

After the initial onset, the subsequent propagation of a disturbance can be seen in the resulting oscillations of voltage and current measurements at strategic locations. In certain locations, such as generator control buses and load centers, the voltage and current contents can be distorted by local control actions and load responses. The locations to best see system oscillations are transmission buses with no nearby generators and loads.

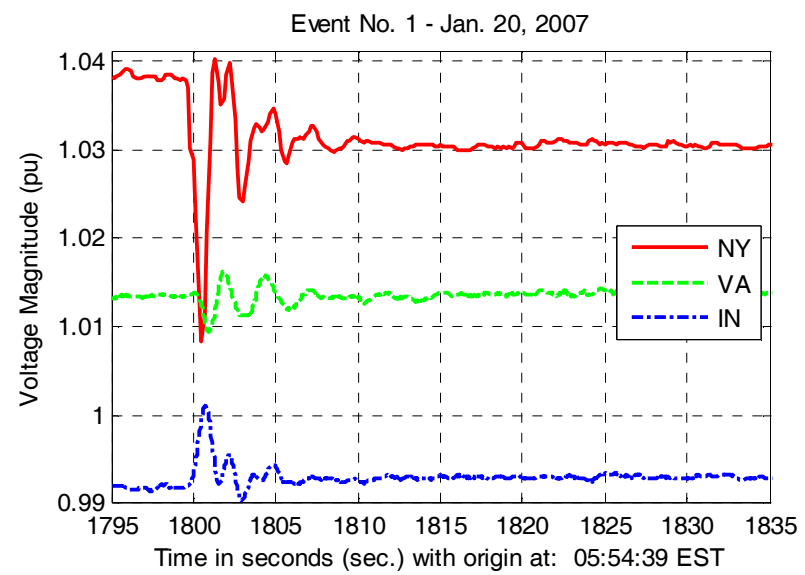

Fig. 5. Voltage responses in three regions.

Fig. 5 shows the voltages on a NY transmission bus close to the disturbance, a transmission bus in Virginia far from the disturbance, and a generator bus in Indiana. The NY bus voltage shows large oscillations, with the local voltage regulation by a STATCOM visible (the dip when voltage goes high). The VA bus voltage shows clear oscillations, but with smaller amplitude. In addition, the voltage oscillations at the NY bus and the VA bus are in phase, although these two buses are several hundred miles apart. The Indiana bus voltage behaved quite differently, as the excitation system of the generator reacted to boost the bus voltage, in order to provide more reactive power to the neighboring buses.

For buses that are close by, the synchrony of voltage responses will be even more pronounced. Fig. 6 shows the voltage responses for several buses in New York in the Northwest region islanding event. The upstate NY (USNY) bus and the western NY (WNY) bus have similar voltage responses. The NY City (NYC) bus, however, has a very different voltage response. This is not unexpected, given the large amount of load in the metropolitan area, which can have very nonlinear dynamic behaviors.

In events involving loss of generation or load, the flows in the system will be redistributed in such a way with generators on regulation compensating for the power imbalance. Fig. 7 shows several line currents in the South Carolina unit trip event, where the flows in Lines 2 and 3 are scaled up by a factor of 2 , for clarity. Line 1 is a major line near the tripped unit, showing a 3 pu decrease in current flow with a damped interarea oscillation initially close to 1 pu peak-to-peak (about 100 MW peak-to-peak). Line 2 is a line farther away, which showed a smaller jump of $0.1 \mathrm{pu}$ and an oscillation amplitude of 0.15 pu peak-to-peak (about $15 \mathrm{MW}$ ). Note that the current magnitude oscillations, like the bus voltage oscillations, are also in phase. Although the generation increase to compensate for the loss of load came from many regions, the increase in flow would cumulate in a few major lines leading into the region with the generation loss. On the other hand, Line 3, which is geographically close to the generation trip area, did not experience a significant change in current magnitude, due to the fact that it is not electrically close.

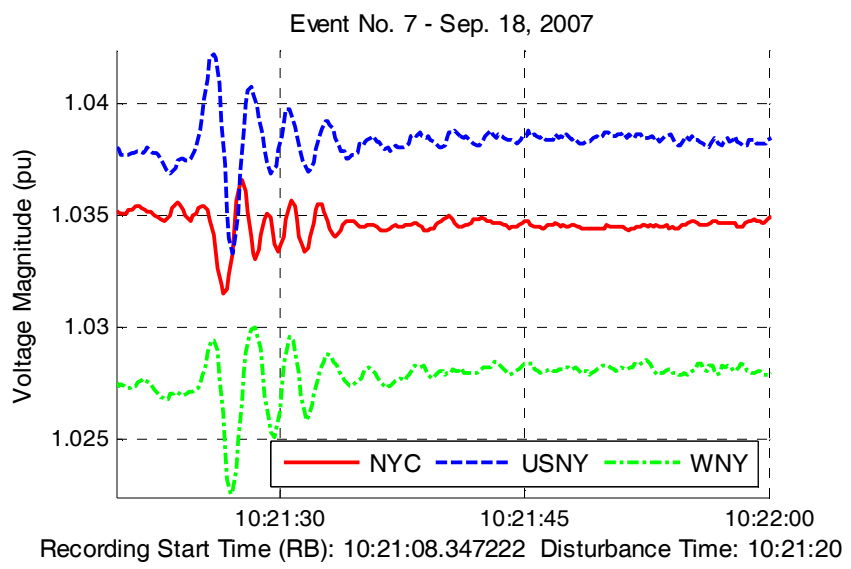

Fig. 6. Voltages in NY

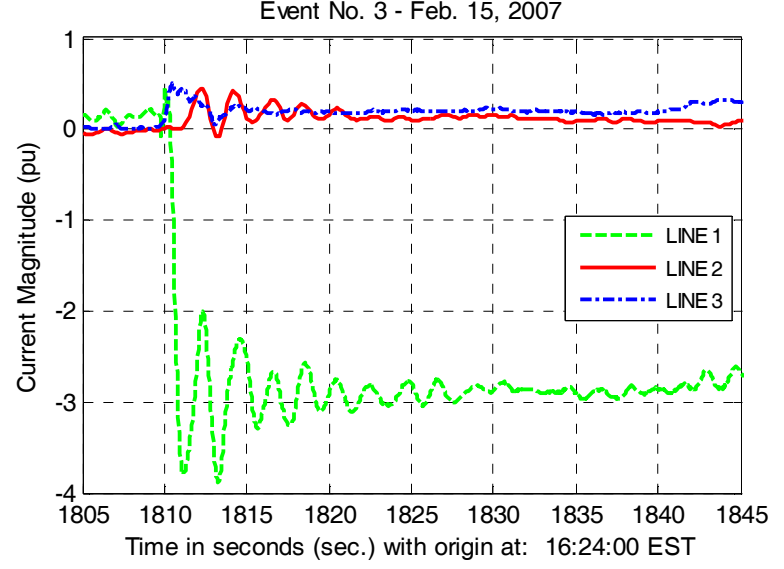

Fig. 7. Line Currents for three lines: Line 1 - Virginia, Line 2 - New York, Line 3 - TVA

Modal analysis results of the voltage and current plots in Figs. 5 and 7 will be presented in the next section.

\section{Post-disturbance steady-state angle change}

From a security assessment point of view, once a system settles to a post-disturbance steady state after loss of generation and/or loss of major transmission lines, there is a 
need to investigate the additional stress on the overall system, because generation in the external regions would have increased, causing more power to flow into the region with generation deficiency. A good indicator of system stress is the incremental angular separation between control regions following the disturbance.

Ideally, one should measure the angular changes between load centers in different control regions. Because of the limited availability of PMU locations and data, only the incremental angular separations between a transmission bus in New York and two transmission buses, one in AEP and one in TVA, were computed, which are shown in the last two columns of Table 1.

The changes in the bus angular separation in Events 3, 5, 6, $7,8,9$, and 10 are consistent with the location of loss of generation. For example, in Event 5, with the loss of a unit in Ohio, the NY generators supplied additional power to Ohio, which advanced the bus angle in NY relative to that in AEP. On the other hand, in Events 8 and 10, with loss of generation to the east of NY, the AEP bus angle advanced more than that of NY. In Event 1, both NY and AEP provided additional power to Ontario from the east and the west, respectively. The angle change indicates that most of the additional flows had gone through NY.

It would be desirable to develop some sensitivities on how the angle separations between NY-AEP and NY-TVA would depend on the amount of generation lost. At this point, we do not have enough disturbance events and measurements to develop such sensitivities. Furthermore, PMUs at additional locations would be desirable.

\section{INTERAREA MODE FREQUENCIES, DAMPING, AND MODE- SHAPES}

The Prony method has been popular in computing the interarea modes from measured responses [17]. Here we used the Hankel-matrix based Eigensystem Realization Algorithm (ERA) $[18,19]$ as it can be readily extended to simultaneous modal identification of multiple signals. This ability is helpful in improving the accuracy of identified modes and reducing the probability of mis-identification.

The results of applying the ERA to the voltage and current signals in Figs. 5 and 7 are shown in Figs. 8 and 9, respectively. The ERA has successfully identified the key oscillatory components in the signals and approximated them with a few oscillatory modes. For the simultaneous identification, only the interarea modes are plotted, emphasizing the in-phase voltage and current time responses at locations that are hundreds of miles apart.

Table 2 shows the results of modal identification for the Event 1 signals in Fig. 8. Single-channel identification for the NY and VA voltages shows an interarea mode of about $0.4 \mathrm{~Hz}$ in each signal. Using simultaneous multiple-channel identification, these two modes coalesce into a single mode at $0.3781 \mathrm{~Hz}$, and a 0.19 damping ratio is found. (A 0.19 damping ratio in a second-order system would produce 2 noticeable oscillations in a step response.)
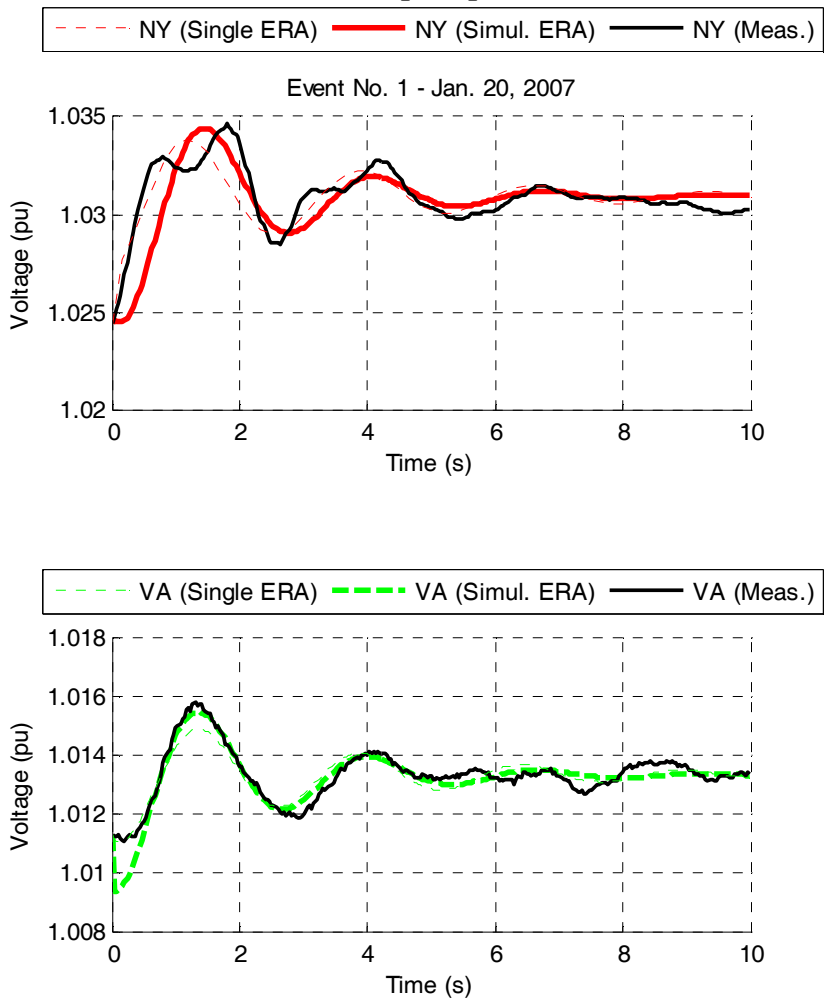

Fig. 8. ERA Identification for the Signals in Fig. 5. (Single ERA: Single channel ERA Identification, Simul. ERA: Simultaneous Multiple channel Signals ERA Identification, Meas.: Measurement)
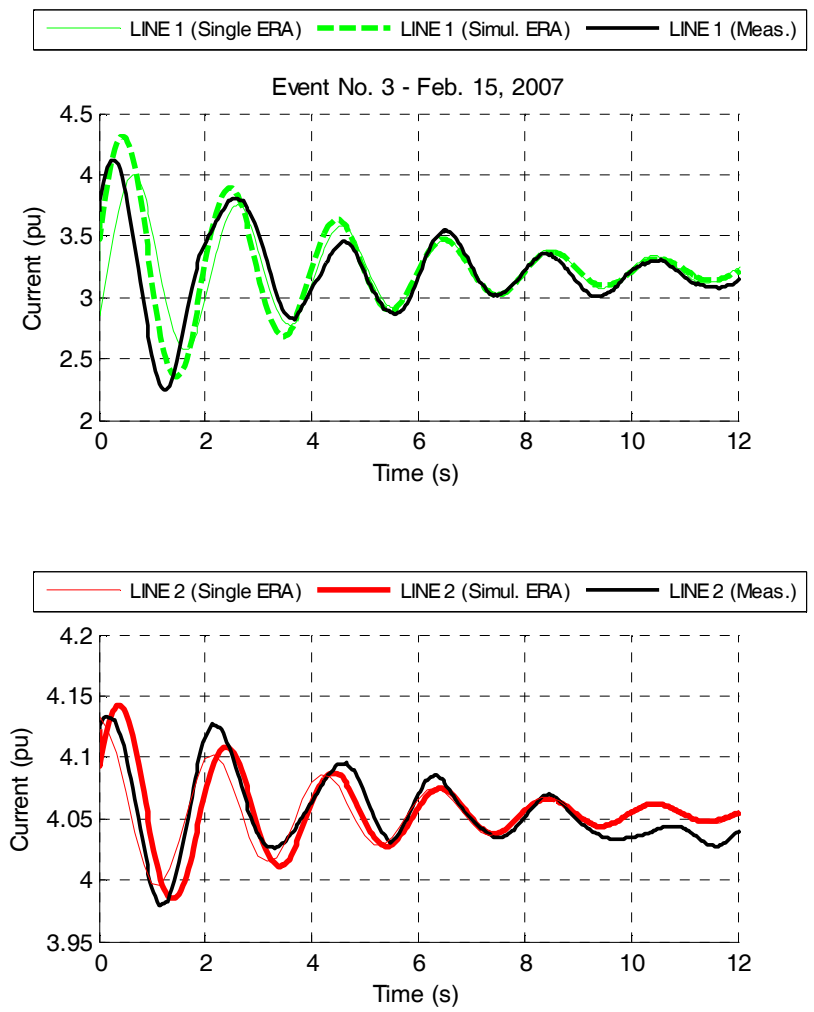

Fig. 9. ERA Identification for the Signals in Fig. 7 


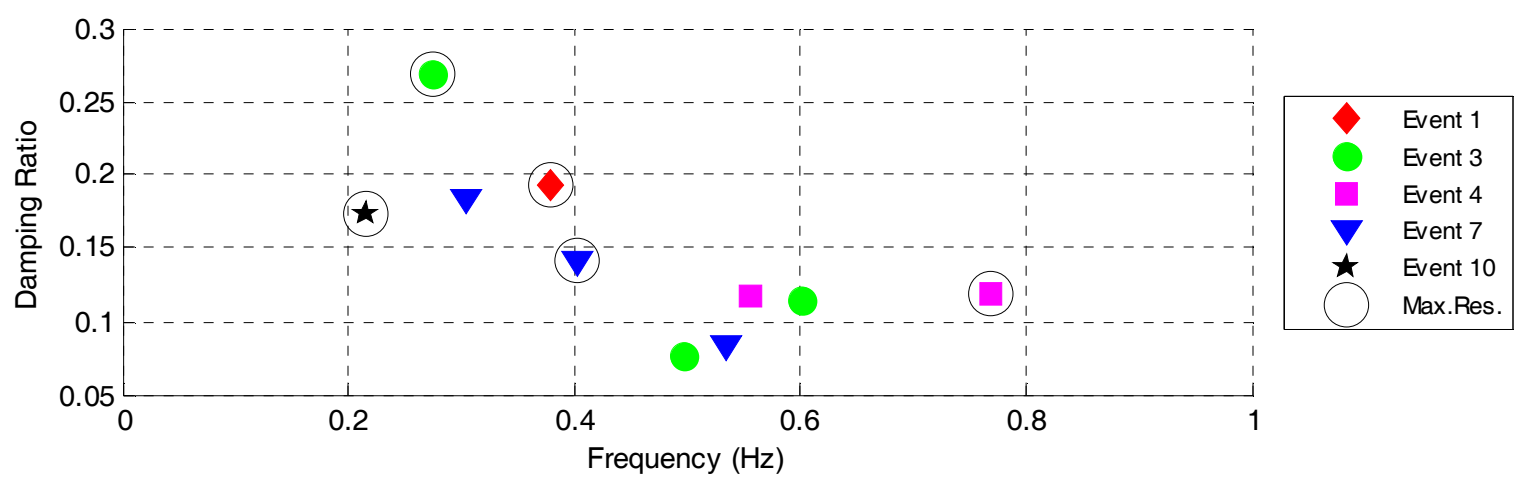

(a) Damping Ratio vs. Frequency

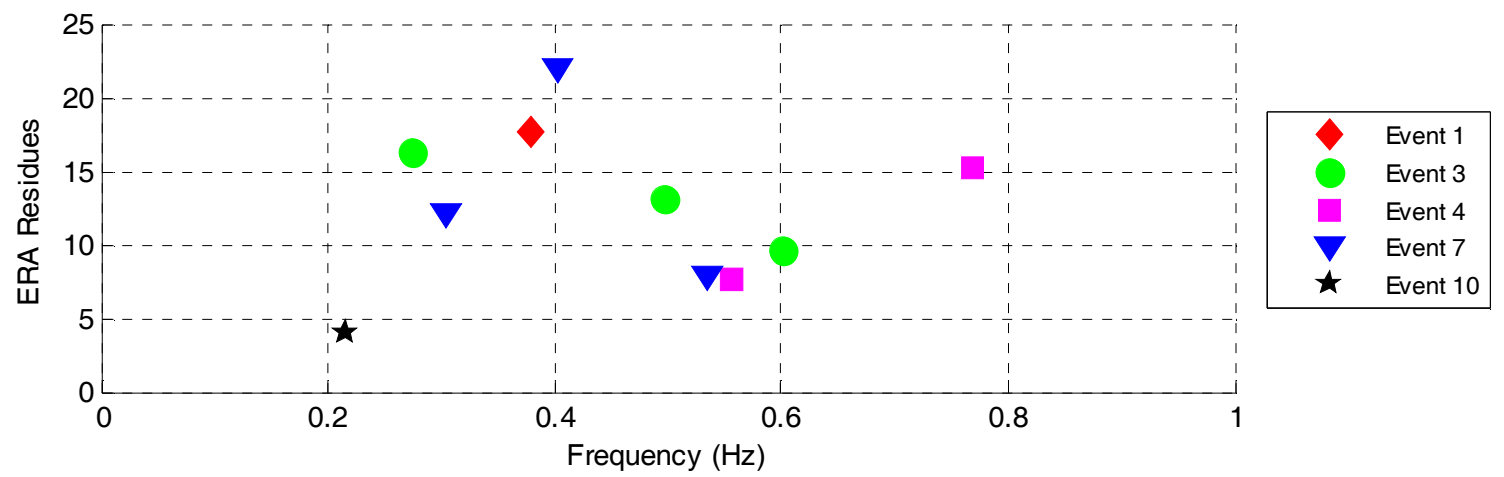

(b) ERA Residues vs. Frequency

Fig. 10. ERA Identification for Events in Table I showing only simultaneous identification: (a) Damping Ratio vs. Frequency, (b) ERA Residue vs. Frequency. Note: Max.Res.: Maximum Residue per Event.

TABLE 2. Modal IDENTIFICATION FOR EVENT NO. 1

\begin{tabular}{|c|c|c|c|c|}
\hline $\begin{array}{c}\text { EVENT NO. 1 } \\
\text { SignALS }\end{array}$ & FREQUENCY & DAMPING & RESIDUE & ENERGY \\
\hline NY & 0.3701 & 0.1264 & 1.8726 & 0.9794 \\
\hline VA & 0.3966 & 0.1176 & 14.1961 & 0.9081 \\
\hline $\begin{array}{c}\text { Simultaneous } \\
\text { Identification }\end{array}$ & 0.3781 & 0.1928 & 17.5956 & 0.6319 \\
\hline
\end{tabular}

The ERA has also been applied to selective disturbances in Table 1 to compute the interarea mode frequencies and damping. The results on modal frequencies, damping, and amplitude (residue) are plotted in Fig, 10. In Fig. 10(a), the mode with the largest amplitude of oscillation in each event has been circled. The damping ratios of these most significant modes are above 0.1 , indicating at most $4-5$ cycles of oscillations.

\section{CONCLUSIONS}

In this paper, we have provided a preliminary analysis of the PMU data for a collection of events in the US Eastern Interconnection. The events show that even for the trip of a large generator of about $1000 \mathrm{MW}$, the measured responses may not exhibit system characteristics suitable for detailed analysis. This is partly due to interarea mode damping ratios higher than 0.1 .

Not covered in this report is ambient analysis of identifying the interarea modes and their damping from ambient data. This activity is ongoing [20] and will be reported separately.

\section{ACKNOWLEDGMENT}

We would like to thank Ritchie Carroll, Paul Trachian, and Lisa Beard of TVA, Jeremiah Stevens of NYISO, Mark Graham, Dr. Bruce Fardanesh, and Dr. Edvina Uzunovic of NYPA, Dr. Yilu Liu of Virginia Tech, Dr. John Pierre of University of Wyoming, and Dr. Daniel Trudnowski of Montana Tech. The views expressed in this paper are solely those of the authors, and do not necessarily represent those of their respective professional affiliations.

\section{REFERENCES}

[1] J. F. Hauer, D. J. Trudnowski, G. J. Rogers, W. A. Mittelstadt, W. H. Litzenberger, and J. M. Johnson, "Keeping an Eye on Power System Dynamics," IEEE Computer Applications in Power, pp. 50-54, October 1997.

[2] U.S.-Canada Power System Outage Task Force. (2004), Final Report on the August 14, 2003 Blackout in the United States and Canada: Causes and Recommendations. [Online]. Available: http://www.nerc.com.

[3] D. N. Ewart, "Whys and Wherefores of Power System Blackouts," IEEE Spectrum, pp. 48-53, April 1978.

[4] G. D. Friedlander, "What Went Wrong VIII: The Great Blackout of '65," IEEE Spectrum, pp. 83-86, October 1976.

[5] J. Ingleson and M. Nagle, "Decline of Eastern Interconnection Frequency Response," in Proceedings of the 1999 Fault and Disturbance Conference, Georgia Tech, May 1999.

[6] A. Bykhovsky and J. H. Chow, "Power System Disturbance Identi-fication from Recorded Dynamic Data from Northfield Substation," Int. J. Elect. Power Energy Syst., vol. 25, no. 10, pp. 787-795, Dec. 2003.

[7] J. E. Dagle, "North American SynchroPhasor Initiative," in Proceedings of the 41st Annual Hawaii International Conference on System Sciences (HICSS 2008), pp. 165-168, 2008. 
[8] A.G. Phadke, "The Wide World of Wide-area Measurement," IEEE Power and Energy Magazine, vol. 6, no. 5, pp. 52-65, September-October, 2008.

[9] J. F. Hauer and J. M. Johnson, A User Guide to PSM Tools: Utilities for Matlab Processing of Power System Response Records. Prepared for the U.S. Department of Energy Transmission Reliability Program by the Consortium for Electric Reliability Solutions (CERTS), February 2001. Available online at: ftp.bpa.gov/outgoing/WAMS\%20Information/

[10] "IEEE standard Common Format for Transient Data Exchange (COMTRADE) for power systems," IEEE Std C37.111-1999, 1999.

[11] R. Almgren, MySQL Client for MATLAB. Available online at: http://www.courant.nyu.edu/ almgren/mysql/

[12] The MathWorks, Database Toolbox User's Guide, Natick, MA: 2008.

[13] R.L. Cresap and J.F. Hauer, "Emergence of a New Swing Mode in the Western Power System," IEEE Transactions on Power Apparatus and Systems, vol. PAS-100, no. 4, pp. 2037-2045, April 1981.

[14] M. Parashar, J. S. Thorp, and C. E. Seyler, "Continuum Modeling of Electromechanical Dynamics in Large-scale Power Systems," IEEE Transactions on Circuits and Systems I: Regular Papers, vol. 51, no. 9, pp. 1848-1858, Sept. 2004.

[15] R. M. Gardner, L. Wei, J. West, J. Dong, Y. Liu, and G. Zhang, "Power System Frequency Oscillation Characteristics," in Proceeding of the 2008 IEEE Power and Energy Society General, July 2008.

[16] J. Zuo, M. Baldwin, H. Zhang, J. Dong, K. Kook, K. Soo, and Y. Liu, "Use of Frequency Oscillations to Improve Event Location Estimation in Power Systems," in Proceeding of the 2007 IEEE Power Engineering Society General Meeting, June 2007.

[17] J. F. Hauer, C. J. Demeure, and L. L. Scharf, "Initial Results in Prony Analysis of Power System Response Signals," IEEE Transactions on Power Systems, vol. 5, no. 1, pp. 80-89, Feb. 1990.

[18] J. Juang, Applied System Identification, Englewood Cliffs, NY: PTR Prentice-Hall, 1994.

[19] J.J. Sanchez-Gasca and J. H. Chow, "Computation of Power System Loworder Models from Time Domain Simulations using a Hankel matrix," IEEE Transactions on Power Systems, vol.12, no.4, pp.1461-1467, Nov. 1997

[20] L. Dosiek, D. J. Trudnowski and J. W. Pierre, "New Algorithms for Mode Shape Estimation using Measured Data," in Proceedings of the 2008 IEEE Power and Energy Society General Meeting, July 2008.

Joe H. Chow (F'92) received his MS and PhD degrees from the University of Illinois, Urbana-Champaign. After working in the General Electric Power System business in Schenectady, he joined Rensselaer Polytechnic Institute in 1987. He is a professor of Electrical, Computer, and Systems Engineering and the Associate Dean of Engineering for Research and Graduate Programs. His research interests include multivariable control, power system dynamics and control, voltage-sourced converter-based FACTS Controllers, and synchronized phasor data.

Luigi Vanfretti (S'03) received the B.S.E.E. degree from Universidad de San Carlos de Guatemala, Guatemala City, in June 2005. He is pursuing the Ph.D. degree in the Electrical, Computer, and Systems Engineering Department at Rensselaer Polytechnic Institute, Troy, NY, from where he obtained the M.S. degree in Electric Power in August 2007. His research interests are dynamics, stability, control, and security of power systems.

Andrew Armenia received the B.S. degree in Electrical Engineering and Computer and Systems Engineering from Rensselaer Polytechnic Institute in May of 2008. He is currently pursuing an M.S. degree in the Department of Electrical, Computer, and Systems Engineering at RPI. His research interests are in computer networks as applied in power systems.

Scott Ghiocel received the B.S.E.E. degree from Rensselaer Polytechnic Institute, Troy, New York, in December 2007. He is currently pursuing the M.S. degree in the Electrical, Computer, and Systems Engineering Department at Rensselaer Polytechnic Institute. His research interests include modeling, control, and dynamics of power systems.

Sanjoy Sarawgi (M'03) received his B. Tech (Hons) from Indian Institute of Technology, Kharagpur, India, in 2002 and MS from Washington State University in 2004.Since 2004, he is with the Advanced Transmission Studies and Technologies section of American Electric Power in Columbus, OH. Sanjoy is a member of the IEEE Power Engineering Society (PES).
Navin Bhatt is AEP's Manager of Advanced Transmission Studies and Technologies. Navin earned his MSEE and PhD degrees from the West Virginia University, Morgantown, WV. Since joining AEP in 1977, he has been involved in conducting, managing and coordinating advanced transmission studies in areas such as stability, generator controls, system restoration and voltage security/collapse. Since 2005, he also has been managing AEP's Transmission R\&D Program. Navin is a member of Eta Kappa Nu honor society, a Senior Member of IEEE, a member of the IEEE Power Engineering Society and a Registered Professional Engineer in the State of Ohio. In addition, for the past 10 years, Navin has been involved in various NERC activities related to power system dynamics, standards development \& compliance, and the 8/14/2003 blackout investigation.

David Bertagnolli is a principal engineer with ISO-New England, the Independent System Operator for the New England bulk electric power system. His responsibilities include the reliable operation of the transmission system, coordination of transmission maintenance, and integration of new generation and technologies. Mr. Bertagnolli joined the New England Power Exchange (NEPEX), predecessor of ISO-New England, in 1985 as an operations engineer responsible for development of network applications in the energy management system. Prior to joining NEPEX, he was a project engineer with the Consolidated Edison Company of New York and a planning engineer with the American Electric Power Company. Mr. Bertagnolli holds a BS degree in electrical engineering from the University of Illinois and a Masters degree from Columbia University. He is a registered professional engineer in the State of Connecticut and a senior member of IEEE.

Meera Shukla is with the Transmission Planning in ISO-New England since June 2007. She received her Master's and Ph.D. in Electrical Engineering from Tennessee Tech University in 2003 and 2007, respectively. Meera had been teaching in Birla Engineering College, India from 1994 to 2001. During her graduate studies she taught in Tennessee Tech University from 2001 to 2007. Her research interests broadly include Power System Optimization and Power System Protection.

Xiaochuan Luo received his PhD from Texas A\&M University in December 1999. He is currently a principal analyst with ISO New England Inc. His research interests include power system planning and operations, power system reliability, visualization of bulk power system, etc. He is a member of the Major System Disturbance Task Force (MSTDF) to investigate and simulate the August 14 Blackout.

Dean Ellis is manager of Short Term Planning for the New York Independent System Operator, Inc, located in Rensselaer, NY. Dean received his B.S. in Electrical Power Engineering from Rensselaer Polytechnic Institute in 1991. Dean is a registered Professional Engineer in New York.

Dawei Fan received his $\mathrm{PhD}$ degree in electrical engineering from Virginia Tech in 2008. He is currently with NYISO as a system and resource planning engineer. His research and work interests include synchronized phasor measurements, protective relaying, and power system reliability.

Mahendra Patel (M'74-SM'81) received the B.S. degree in electrical engineering from Sardar Patel University, Vallabhvidyanagar, Gujarat, India, in 1971, the M.S.E.E. degree from West Virginia University, Morgantown, WV, in 1979, and the M.B.A. degree from the University of Pittsburgh, Pittsburgh, PA, in 1983. He has worked in electric power utilities for over 32 years, mainly in the areas of system dynamics, voltage stability, and network transient analysis. He joined PJM, Norristown, PA, in 2002 and is Manager of Generation Analysis, where he is responsible for system dynamics analysis and generation and merchant transmission interconnection planning. Mr. Patel is a member of CIGRE.

Andrew M. Hunter is the Director of Transmission Initiatives for FirstEnergy Corporation. He received a Bachelors Degree in Electrical Engineering from Lafayette College, Easton Pennsylvania and a Master of Business Administration from Saint Joseph's University, Philadelphia Pennsylvania. Andrew is registered Professional Electrical Engineer in the State of Pennsylvania. He has been employed by FirstEnergy and its predecessor companies for 25 years working in Operations and Engineering positions. 
David E. Barber is Supervisor of Transmission Planning for FirstEnergy Corporation. He received a Bachelors Degree in Electrical Engineering and a Masters Degree in Electrical Engineering from Virginia Polytechnic Institute and State University in 1991 and 1994, respectively. David is a registered Professional Electrical Engineer in the State of Pennsylvania. He has been employed by FirstEnergy and its predecessor companies for 15 years working in planning and protective relaying positions.

Gary L. Kobet is an Operations Engineer for the Tennessee Valley Authority (TVA) in Chattanooga, Tennessee. His responsibilities include performing voltage and generator stability studies for the operating horizon, as well as developing operational tools to monitor reactive reserve within the TVA service area. Previously he worked in TVA's System Protection department planning relaying schemes for transmission and generation projects, as well as calculating relay setpoints and performing post-fault analysis. He has performed transient studies using EMTP for breaker TRV studies and switching surge overvoltages. Previously he worked as a field engineer and as power quality specialist. Mr. Kobet earned the B.S.E. (electrical) from the University in Alabama in Huntsville in 1989 and the M.S.E.E. from Mississippi State University in 1996. He was a member of the NERC System Protection \& Control Task Force from 2004-2005. He is a senior member of the IEEE Power Engineering Society and is active in the Power System Relaying Committee, having participated in several working groups, and is a member of the PSRC's Rotating Machinery Subcommittee, System Protection Subcommittee, and Line Protection Subcommittee. He is also a member of CIGRE, Eta Kappa Nu, Tau Beta Pi, and is a registered professional engineer in the State of Alabama. 